\title{
Highly Sensitive Halide Ions Recognition with Diprotonated Porphyrin
}

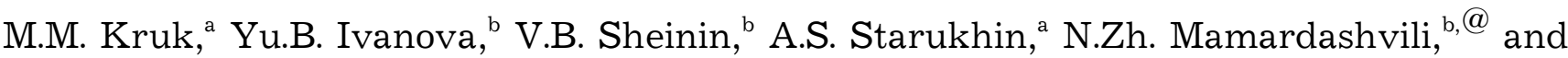 \\ O.I. Koifman ${ }^{\mathrm{b}}$
}

\author{
${ }^{a}$ B.I. Stepanov Institute of Physics of National Academy of Sciences, Minsk, 220072, Belarus \\ ${ }^{\mathrm{b}}$ Institute of Solution Chemistry of Russian Academy of Sciences, Ivanovo, 153045, Russia \\ @ Corresponding authorE-mail: ngm@isc-ras.ru
}

\begin{abstract}
The titration of the diprotonated form of 3,7,13,17-tetramethyl-2,8,12,18-tetrabutylporphyrin with the series of halide ions has been done in the acetonitrile solution. It was shown that the stable complexes of 1:1 and 1:2 structures with halide ions have been formed. The influence of complexation with halide ions on the porphyrin fluorescent properties has been studied. The strong quenching of the porphyrin fluorescence has been found. It was established that both static quenching upon the nonfluorescent complex formation due to internal heavy atom effect and dynamic diffusioncontrolled quenching took place. Based on the analysis of dependencies of fluorescence intensity and lifetime on the iodide ions concentration in solution, it was proposed to use the diprotonated form of the porphyrin as a basic compound for design of the fluorescent molecular receptor for the halide ions.
\end{abstract}

\section{Introduction}

The design of new efficient means for real-time detection of chemical and biochemical species through the use of sensors is among the most significant fields in modern science. ${ }^{[1]}$ The nature of the molecular sensing agent used to generate the chemical diagnostic signal upon the recognition of the given substance is central to determining the overall performance of any chemical sensor. The way of transduction of this chemical signal into appropriate analytical signal is also of great importance since it determines the ease of production and exploitation of the sensing device. The optical transduction seems to be the most attractive for several reasons which include inherent safety, less noise pickup in signal transmission over long distances, and the possibility of obtaining much more comprehensive information from a single probe.

The representatives of the tetrapyrrolic compounds family can serve as good candidates for optical transduction. They are known to have rather strong luminescence (fluorescence and/or phosphorescence) that can be tuned in the appropriate spectral range by modification of the molecule. The sensitivity of the rate constant and quantum yield of porphyrin luminescence to the properties of molecular microenvironment provides the possibility to use tetrapyrrolic molecules not only as optical transducers but as sensing agents also. Design of the molecular sensor can be simplified in such a case, since the same molecule combines both functions.

Anions play a fundamental role in a wide range of chemical and biological processes, and numerous efforts have been devoted to the development of abiotic receptors for anion species, ${ }^{[2]}$ but they are still very limited. The detection of different anions in the solution can be achieved with using of tetrapyrrolic compounds. The diprotonated forms of tetrapyrrolic compounds are able to form adducts with the organic and inorganic acid residues ${ }^{[3-5]}$ and to form complexes with salt anions. ${ }^{[6,7]}$ The large efforts has been made in the elucidation of the molecular conformation, ${ }^{[3,5,8-16]}$ acid-base equilibria involved ( ${ }^{[17-21]}$ and Refs. therein), ground and excited states properties ${ }^{[4,15,20-24]}$ of the diprotonated porphyrins. The essential progress has been achieved in this area. It was found, that upon protonation of the macrocycle core the nonplanar conformation is adopted. $^{[3,5,8-16]}$ The type and extent of macrocycle nonplanar distortions have been extensively discussed in terms of molecular flexibility, ${ }^{[5,10]}$ pattern of the peripherical substitution, ${ }^{[5,8,10,15,16,22]}$ strength of intermolecular interactions with acid residues. ${ }^{[3,5,11,12,15]}$ The relationship between the molecular structure and macrocycle core acidity-basicity equilibrium has been studied, ${ }^{[18-21]}$ and the intermediate monoprotonated form has been characterized for several tetrapyrrolic compounds. ${ }^{[20,21,25-27]}$ The dramatic changes in the rates and channels of the excitation energy deactivation have been documented in going from the free base to diprotonated compounds, ${ }^{[4,20-23]}$ and different mechanisms involved in these changes were proposed. ${ }^{[4,15,22-24]}$

One of the most interesting issues from point of view of possible practical applications is the interaction of diprotonated macrocycle with anions. The X-ray studies, ${ }^{[3,5]}$ NMR, IR, Raman and UV-vis spectroscopies, ${ }^{[6,7,25,28]}$ theoretical calculations ${ }^{[11,12,15,24]}$ have been applied to study this problem. It was established that both in solid state and in liquid organic solutions the hydrogen bonding between the positively charged core protons and anions occurs, ${ }^{[3-}$ ${ }_{5,15,16]}$ and the properties of this bond has been extensively discussed. The most of these studies have focused mainly on the structural aspects ${ }^{[3,5,15]}$ or the consequences of this hydrogen bond formation for the photophysical properties of diprotonated compounds. ${ }^{[3,22,24]}$ The detailed studies of the complexation constants and the relationship between amount of the salt added and the spectral response of porphyrin have received much less attention. ${ }^{[7,30-32]}$ In this 
work we report the experimental results on the recognition of halide ion salts in solution with the diprotonated form of 3,7,13,17-tetramethyl-2,8,12,18-tetrabutylporphyrin

(Figure 1). The fluorometric and spectropotentiometric titration experiments have been done. The mechanisms of the diprotonated porphyrin fluorescence quenching upon complexation with halide ions are studied. We discuss the possibility of using of diprotonated porphyrins as the basic compounds in the design of new efficient fluorescent molecular sensors for recognition of halide ions and measurements of halide ion salts concentration in the solutions.

\section{Experimental}

\section{Materials and Methods}

3,7,13,17-tetramethyl-2,8,12,18-tetrabutylporphyrin (Figure 1) was prepared using method described elsewhere. ${ }^{[33]}$ The identity of the structure was checked by spectroscopic methods and was found to correspond to the literature data. ${ }^{[34]}$ The halide salts and perchloric acid solutions were prepared with carefully dried acetonitrile. Acetonitrile was purified with dynamic drying on the column with neutral aluminium oxide and with following rectification. ${ }^{[35]}$ Potassium iodide (KI) and sodium iodide (NaI) were dried under vacuum $(1.33 \mathrm{~Pa})$ at $393 \mathrm{~K}$ during 48 hours until the constancy of mass has been achieved. The perchloric acid as $8.75 \mathrm{M}$ water solution was used for the preparation of the $0.01 \mathrm{M}$ $\mathrm{HClO}_{4}$ solution in dried acetonitrile (water content in dried acetonitrile was no more than $0.01 \mathrm{M}$ ). The total amount of water added to the solutions in the most acidic solution $(\mathrm{p} H=4.5)$ was calculated to be about $0.011 \mathrm{M}$. The value was estimated by the method of Fischer titration. Tetraethylammonium bromide $\left(\mathrm{Et}_{4} \mathrm{NBr}\right)$ was recrystallized twice from acetonitrile and dried in vacuum-desiccator over $\mathrm{NaOH}$ during 24 hours at $293 \mathrm{~K}$. Tetraethylammonium chloride $\left(\mathrm{Et}_{4} \mathrm{NCl}\right)$ was recrystallized twice from acetonitrile and dried under vacuum (1.33 Pa) during 24 hours at $293 \mathrm{~K}$. The halide salts were chosen taking into account their dissociation degrees in acetonitrile. ${ }^{[36-39]}$

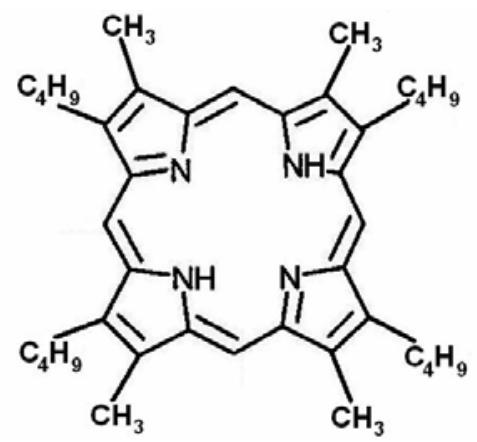

Figure 1. Structure of 3,7,13,17-tetramethyl-2,8,12,18tetrabutylporphyrin.

The spectrophotometric titration of the diprotonated species $\mathrm{H}_{4} \mathrm{P}^{2+}$ with halide ion salts was carried out at $\mathrm{pH}=6.5$, which has been maintained with microaddition of $0.05 \mathrm{~N}$ solution of perchloric acid in acetonitrile. At the each titration step the analytical concentrations of reagents were corrected for dilution according to the equation $A_{\mathrm{T}}=A_{\mathrm{T}}^{0} /\left(1+\sum \Delta V / V_{0}\right)$, where $V_{0}$ is an initial solution volume, $\Sigma \Delta V$ is a sum of titrants, $A_{\mathrm{T}}$ is a current optical density value at the analytical wavelength taking into account the titrants added, $A_{\mathrm{T}}^{0}$ is a measured current optical density at the analytical wavelength.

For the fluorescent experiments the porphyrin powder were dissolved in the acetonitrile that contained the chloric acid in the amount required for the complete transformation of all the porphyrin molecules from free base form into diprotonated form $(\mathrm{pH}=6.5) .{ }^{[31]}$ Titration of the porphyrin samples with potassium iodide was done with addition of the small amounts of the concentrated potassium iodide solution that were prepared in the same acidificated acetonitrile as the porphyrin sample.

The concentration of diprotonated porphyrin in solutions was determined spectrophotometrically with known extinction coefficients $\left(\varepsilon=8710 \mathrm{M}^{-1} \mathrm{~cm}^{-1}\right.$ at $585 \mathrm{~nm}, \varepsilon=28180 \mathrm{M}^{-1} \mathrm{~cm}^{-1}$ at $543 \mathrm{~nm}, \varepsilon=102330 \mathrm{M}^{-1} \mathrm{~cm}^{-1}$ at $\left.403.7 \mathrm{~nm}^{[34]}\right)$ and was $\sim 2 \cdot 10^{-6}$ and $1.5 \cdot 10^{-5} \mathrm{M}$ in the fluorometric and spectropotentiometric titration experiments, respectively. The cell for the studies of the acid-base equilibria and the procedure of the spectropotentiometric titration in acetonitrile were described in details. ${ }^{[30]}$ Electronic absorption spectra were measured with CARY 500 Scan (Varian).

The fluorescence measurements was done in the standard quartz rectangular cells $(1 \times 1 \mathrm{~cm}$, Hellma) in the air equilibrated solutions at $293 \pm 2 \mathrm{~K}$. The deoxygenated solutions were used for the measurements of the fluorescence quantum yield $\Phi_{\mathrm{fl}}$ of the diprotonated form of 3,7,13,17-tetramethyl-2,8,12,18tetrabutylporphyrin (hereafter referred as $\mathrm{H}_{4} \mathrm{P}^{2+}$ ). Deoxygenation of the solutions has been performed with argon bubbling during 20 min just before measurements. The fluorescence spectra and fluorescence excitation spectra were measured using of spectrofluorometer SFL-1211 (Solar). The fluorescence decay kinetics was measured with the using of photon counting system (Edinburgh Instruments). The fluorescence quantum yield $\Phi_{\mathrm{fl}}$ was determined using the standard sample method. ${ }^{[40]}$ The free base 5,10,15,20-tetraphenylporphyrin $\left(\mathrm{H}_{2} \mathrm{TPP}\right)$ was taken as a standard sample $\left(\Phi_{\mathrm{fl}}^{0}=0.11^{[41]}\right)$.

\section{Results and Discussions}

\section{Acid-base Equilibria of Macrocycle}

Prior the studies of porphyrin interactions with halide ions the acid-base equilibria of 3,7,13,17-tetramethyl2,8,12,18-tetrabutylporphyrin have been studied with the use of the spectropotentiometric titration method. Titration was carried out in acetonitrile with $0.01 \mathrm{M}$ perchloric acid solution. In this case the perchloric acid is completely dissociated and porphyrin protonation occurs by means of solvated proton $\left(\mathrm{p} K_{\mathrm{a}}^{298}=2.8^{[42,43]}\right)$. The corresponding titration curve reveals two steps (Figure 2).

This observation indicates that successive formation of the monoprotonated $\mathrm{H}_{3} \mathrm{P}^{+}$and diprotonated species $\mathrm{H}_{4} \mathrm{P}^{2+}$ takes place upon increase in the concentration of perchloric acid. The difference in the equilibrium constants for the formation of mono- and diprotonated species $\left(K_{\mathrm{a} 1}\right.$ and $\left.K_{\mathrm{a} 2}\right)$ is three orders of magnitude $\left(K_{\mathrm{a} 1}=(1.66 \cdot \pm 0.05) \cdot 10^{12} \mathrm{M}^{-1}\right.$ and $\left.K_{\mathrm{a} 2}=(1.66 \pm 0.05) \cdot 10^{9} \mathrm{M}^{-1}\right)$. Therefore for the given system "porphyrin - acetonitrile - perchloric acid" three $\mathrm{p} H$ ranges are available in which the studied molecules exist either exclusively in the free base $\mathrm{H}_{2} \mathrm{P}(\mathrm{pH}>15)$ or diprotonated $\mathrm{H}_{4} \mathrm{P}^{2+}$ forms $(\mathrm{pH} \leq 7)$ or mainly in the monoprotonated $\mathrm{H}_{3} \mathrm{P}^{+}$form $(\mathrm{pH}=9-11)$. The electronic absorption spectra in the $Q$ band range for each of the free base $\mathrm{H}_{2} \mathrm{P}$, monoprotonated $\mathrm{H}_{3} \mathrm{P}^{+}$and diprotonated $\mathrm{H}_{4} \mathrm{P}^{2+}$ forms are shown in Figure 3. 


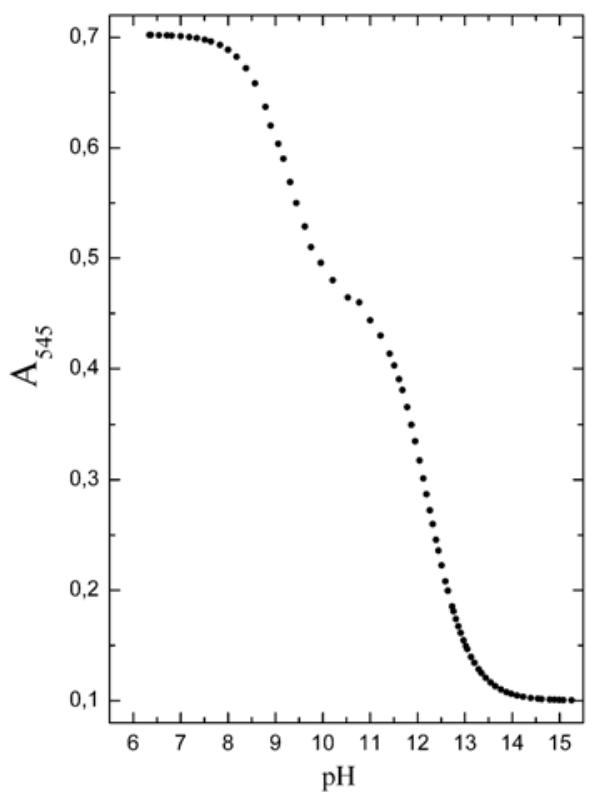

Figure 2. Absorption titration curve at $\lambda=545 \mathrm{~nm}$ for $3,7,13,17$-tetramethyl-2,8,12,18-tetrabutylporphyrin in acetonitrile at $298 \mathrm{~K}$.

\section{Spectropotentiometric Titration with Halide Ions}

The diprotonated form $\mathrm{H}_{4} \mathrm{P}^{2+}$ was titrated with three halide ion salts. Electronic absorption spectra (Figure 4) indicate that increase of halide ion concentration $\left[\mathrm{X}^{-}\right]$ leads to the red shift of the porphyrin absorption bands indicating that the complexation takes place. The two sets of the isobestic points during the transformation of the absorption spectra were identified for each of the studied halide ions. These isobestic points are related to the equilibria (1) and (2) respectively:

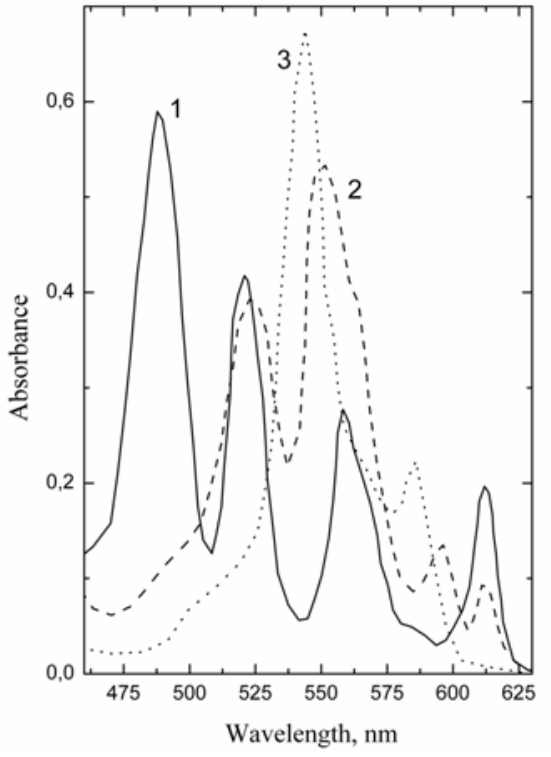

Figure 3. Electronic absorption spectra in the $Q$-band region: free base $\mathrm{H}_{2} \mathrm{P}(1)$, monoprotonated $\mathrm{H}_{3} \mathrm{P}^{+}(2)$ and diprotonated $\mathrm{H}_{4} \mathrm{P}^{2+}$ (3) forms. Porphyrin concentration is $1.5 \cdot 10^{-5} \mathrm{M}$.

$$
\begin{aligned}
& \mathrm{H}_{4} \mathrm{P}^{2+}+\mathrm{X}^{-} \stackrel{K_{1}}{\longrightarrow} \mathrm{H}_{4} \mathrm{P}^{2+} \cdot \mathrm{X}^{-} \\
& \mathrm{H}_{4} \mathrm{P}^{2+} \cdot \mathrm{X}^{-}+\mathrm{X}^{-} \stackrel{K_{2}}{\longrightarrow} \mathrm{H}_{4} \mathrm{P}^{2+} \cdot 2 \mathrm{X}^{-},
\end{aligned}
$$

where the constant $K_{1}$ is referred to the formation of porphyrinhalide ion complex with 1:1 ratio, and the constant $K_{2}$ is related to the complex with 1:2 ratio. The isobestic points for the equilibrium (1) have been measured as 526 and $553 \mathrm{~nm}, 548$ and $590 \mathrm{~nm}, 549$ and $590 \mathrm{~nm}$ in case of iodide, bromide and chloride ions, respectively. For equilibrium (2) the isobestic points are 528 and $555 \mathrm{~nm}, 550$ and $592 \mathrm{~nm}, 552$ and $593 \mathrm{~nm}$, in case of iodide, bromide and chloride ions, respectively.
$\boldsymbol{A}$

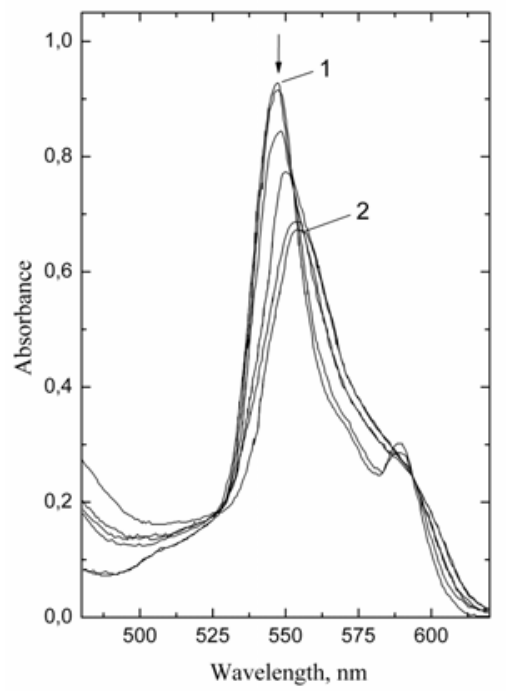

B

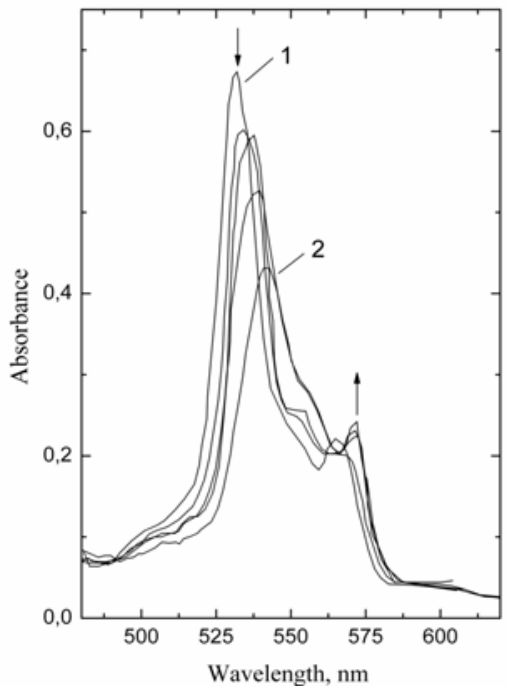

C

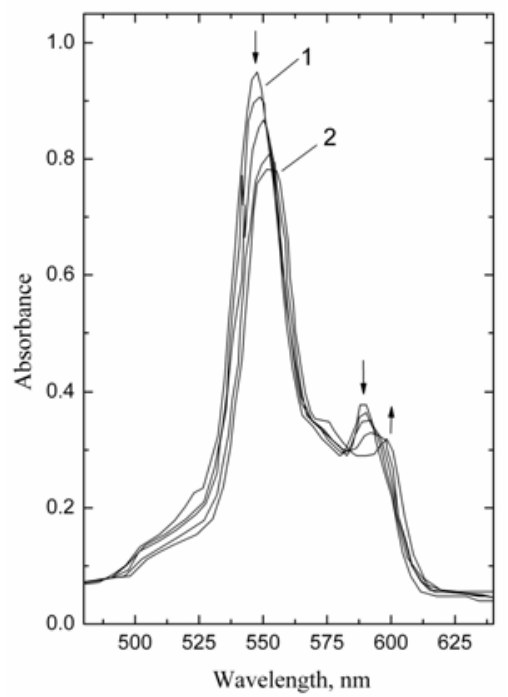

Figure 4. The transformation of the electronic absorption spectra of $\mathrm{H}_{4} \mathrm{P}^{2+}$ upon the formation of complexes with halogenide ions in acetonitrile at $\mathrm{pH}=6.5: \mathrm{A}$ - titration with $\mathrm{NaI}, 1-\mathrm{H}_{4} \mathrm{P}^{2+}, 2-\mathrm{H}_{4} \mathrm{P}^{2+} \cdot 2 \mathrm{I}^{-} ; B$ - titration with $\mathrm{Et}_{4} \mathrm{NBr}, 1-\mathrm{H}_{4} \mathrm{P}^{2+}, 2-\mathrm{H}_{4} \mathrm{P}^{2+} \cdot 2 \mathrm{Br}^{-} ; C$ - titration with $\mathrm{Et}_{4} \mathrm{NCl}, 1-\mathrm{H}_{4} \mathrm{P}^{2+}, 2-\mathrm{H}_{4} \mathrm{P}^{2+} \cdot 2 \mathrm{Cl}$-. Arrows indicate the direction of the absorbance changes upon formation of the complexes. 
$A$

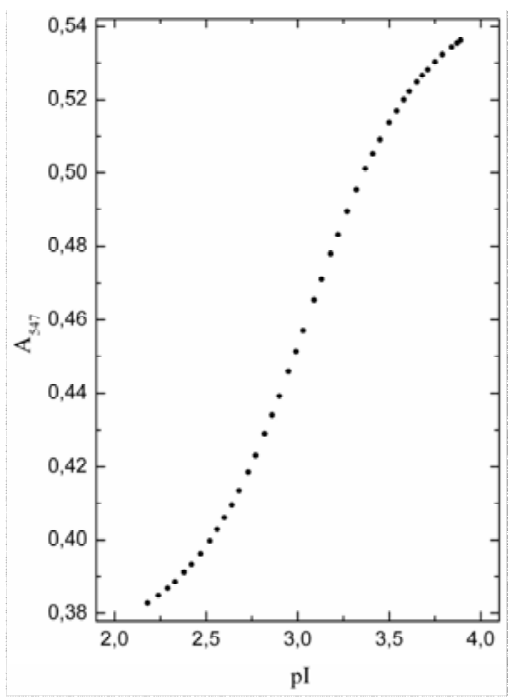

$\boldsymbol{B}$

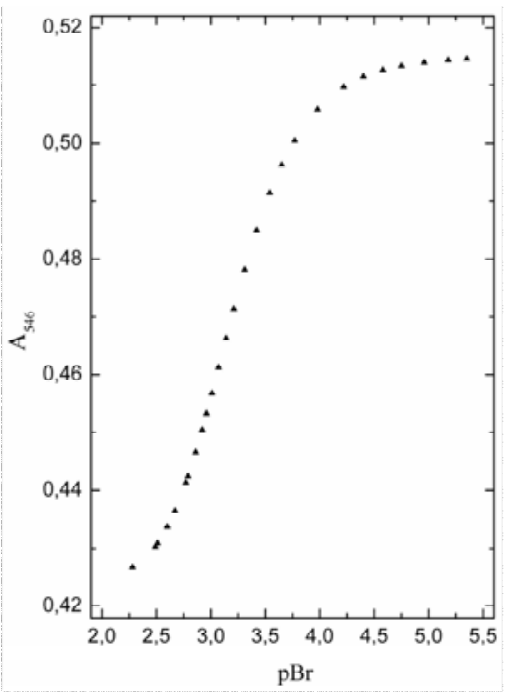

C

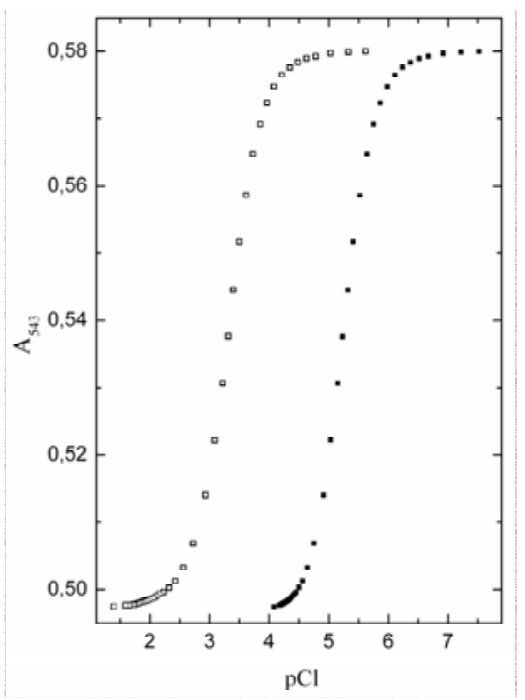

Figure 5. The dependence of the absorbance of the $\mathrm{H}_{4} \mathrm{P}^{2+}$ on the concentration of the halide salts in acetonitrile at $298 \mathrm{~K}: A-\mathrm{NaI}, B$ $\mathrm{Et}_{4} \mathrm{NBr}$ and $C-\mathrm{Et}_{4} \mathrm{NCl}$. Open and closed symbols in case of $\mathrm{Et}_{4} \mathrm{NCl}$ denote the total concentration of salt and the concentration of nonaggregated solvated chloride ions, respectively.

The formation of complexes of diprotonated porphyrin with halide ions was analyzed with the titration curves (Figure 5). There are no two sharp well separated steps at the titration curves which correspond to the equilibria (1) and (2). Such behaviour is characteristic when the constants $K_{1}$ and $K_{2}$ of the conjugated equilibria differ less than two orders of magnitude. ${ }^{[44]}$ However, the values of the

$$
A=\frac{A_{H_{4} P^{2+}}+A_{H_{4} P^{2+} \cdot X^{-}} \cdot\left[X^{-}\right] \cdot K_{1}+A_{H_{4} P^{2+} \cdot 2 X^{-}} \cdot\left[X^{-}\right]^{2} \cdot K_{1} \cdot K_{2}}{1+\left[X^{-}\right] \cdot K_{1}+\left[X^{-}\right]^{2} \cdot K_{1} \cdot K_{2}}
$$

evidence that the complexation constant is very low and the large excess of acid is required to achieve the complexation. ${ }^{[5]}$ In our case the concentration of acid was very low and seems to be insufficient for complexation.

The measured equilibrium constant is strongly influenced by the state of the given ion in the solution. In the case of incomplete dissociation of salts or due to the aggregation phenomena (ion pair formation $^{[45]}$ ) the measured equilibrium constants values may deviate strongly from the actual equilibrium constants $K_{1}$ and $K_{2}$ have been calculated with the nonlinear least-square method for the equation (3) where $A_{H_{4} P^{2+}}, \quad A_{H_{4} P^{2+} \cdot X^{-}}, \quad A_{H_{4} P^{2+} \cdot 2 X^{-}}$are the optical densities measured for the solutions of uncomplexed diprotonated species $\mathrm{H}_{4} \mathrm{P}^{2+}$, monoligated $\mathrm{H}_{4} \mathrm{P}^{2+} \cdot \mathrm{X}^{-}$and diligated $\mathrm{H}_{4} \mathrm{P}^{2+} \cdot 2 \mathrm{X}^{-}$complexes, respectively. During leastsquare fitting $A_{H_{4} P^{2+}}$ and $A_{H_{4} P^{2+} \cdot 2 X^{-}}$values were taken as they have been measured experimentally, and $A_{H_{4} P^{2+} \cdot X^{-}}$value was the variable parameter. The obtained values for the equilibrium constants are presented in Table.

Table. The equilibrium constants $K_{1}$ and $K_{2}$ for the formation of the $\mathrm{H}_{4} \mathrm{P}^{2+}$. X- and $\mathrm{H}_{4} \mathrm{P}^{2+} \cdot 2 \mathrm{X}^{-}$complexes in acetonitrile at $298 \mathrm{~K}$.

\begin{tabular}{lll}
\hline \multicolumn{1}{c}{ Halide ion } & \multicolumn{1}{c}{$K_{1}, \mathrm{M}^{-1 \mathrm{a}}$} & \multicolumn{1}{c}{$K_{2}, \mathrm{M}^{-1 \mathrm{a}}$} \\
\hline $\mathrm{I}^{-}$ & $1.20 \cdot 10^{3}$ & $1.07 \cdot 10^{3}$ \\
$\mathrm{Br}^{-}$ & $2.46 \cdot 10^{3}$ & $1.23 \cdot 10^{3}$ \\
& $4.08 \cdot 10^{3}$ & $1.27 \cdot 10^{3}$ \\
$\mathrm{Cl}^{-}$ & $2.51 \cdot 10^{5 \mathrm{~b}}$ & $2.01 \cdot 10^{5 \mathrm{~b}}$ \\
\hline
\end{tabular}

\footnotetext{
a The error in determination of the $K_{1}$ and $K_{2}$ values is $3-5 \%$.

$\mathrm{b}$ The values are calculated taking into account the aggregation of chloride ions (see text).
}

As for the possible complexation of $\mathrm{ClO}_{4}{ }^{-}$with porphyrin, it can be excluded since the experiments ones. The aggregation of the halide ions has been studied in the separate experiments using the specific ion electrodes Crutur 52-27, 35-27, 17-27. The results of this study indicate that in the acetonitrile solution at $\mathrm{pH}=6.5$ the formation of multiple $\mathrm{H}_{\mathrm{n}} \mathrm{Cl}_{\mathrm{m}}$ aggregates (namely, $\mathrm{HCl}$, $\mathrm{H}_{2} \mathrm{Cl}^{+}, \mathrm{HCl}_{2}{ }^{-}$and $\mathrm{HCl}_{3}{ }^{2-}$ ) takes place. The special procedure has been used to evaluate the true chloride ion concentration. $^{[31]}$ In the Table both the apparent (uncorrected for the aggregation) and true equilibrium constants are given for the $\mathrm{H}_{4} \mathrm{P}^{2+} \cdot 2 \mathrm{Cl}^{-}$complex.

The presented data indicate that the stability of both $\mathrm{H}_{4} \mathrm{P}^{2+} \cdot \mathrm{X}^{-}$and $\mathrm{H}_{4} \mathrm{P}^{2+} \cdot 2 \mathrm{X}^{-}$complexes in acetonitrile increases when the halide ion radius decreases. The complexation constants for the chloride $\left(\mathrm{Cl}^{-}\right)$complexes are about 100 times higher than those for bromide $\left(\mathrm{Br}^{-}\right)$and iodide $\left(\mathrm{I}^{-}\right)$ complexes. Low complexation constants for two last halide ions are likely due to their larger ionic radii as compared with those for the former. These results are in line with the conclusions on the relationship between the size of halide ion and the contribution from orbital and electrostatic interactions energy into the hydrogen bond formation within $\mathrm{H}_{4} \mathrm{P}^{2+} \cdot 2 \mathrm{X}^{-}$complexes. ${ }^{[15]}$ With the relation to the application of the diprotonated form of porphyrin for the ions detection in the solution, the ions aggregation leads to decrease in the sensitivity of measurements. This is because of the porphyrin recognizes the free solvated ions only, and the ionic aggregates (mentioned above) are not bound by diprotonated porphyrin molecule. 
It is significant to note that the monoprotonated $\mathrm{H}_{3} \mathrm{P}^{+}$ molecules do not form stable complexes with halide ions in the same conditions. We have observed the transformation of the $\mathrm{H}_{3} \mathrm{P}^{+}$absorption spectrum into spectrum characteristic for $\mathrm{H}_{4} \mathrm{P}^{2+} \cdot 2 \mathrm{X}^{-}$during titration of $\mathrm{H}_{3} \mathrm{P}^{+}$with halide salts. The calculation of current concentrations of the $\mathrm{H}_{2} \mathrm{P}, \mathrm{H}_{3} \mathrm{P}^{+}, \mathrm{H}_{4} \mathrm{P}^{2+}, \mathrm{H}_{4} \mathrm{P}^{2+} \cdot \mathrm{X}^{-}$and $\mathrm{H}_{4} \mathrm{P}^{2+} \cdot 2 \mathrm{X}^{-}$are in good agreement with the results of the $\mathrm{H}_{3} \mathrm{P}^{+}$titration by halide salts. The anion-induced protonation of monoprotonated species $^{[7]}$ takes place first and the newly formed diprotonated species bind anions.

\section{Structure of Complexes with Halide Ions}

The molecular structure of $\mathrm{H}_{4} \mathrm{P}^{2+} \cdot 2 \mathrm{X}^{-}$complexes with halide ions was the subject of numerous experimental and theoretical investigations. ${ }^{[3,5,8-16]}$ It was shown ${ }^{[3]}$ that $\mathrm{Cl}^{-}$ ions are symmetrically aligned exactly at the porphyrin macrocycle symmetry axis at two sides of the porphyrin plane. The similar results have been obtained later for the complexes of several porphyrins with perchlorate ions $\mathrm{ClO}_{4}{ }^{-}{ }^{[5]}$ The length of the hydrogen bond between the porphyrin core protons and $\mathrm{Cl}^{-}$ions in the complexes $\mathrm{H}_{4} \mathrm{TPP}^{2+} \cdot 2 \mathrm{Cl}^{-}$and $\mathrm{H}_{4} \mathrm{TPyrP}^{2+} \cdot 2 \mathrm{Cl}^{-}$was found to be $\sim 3-$ $4 \AA{ }^{[3]}$ The length of the hydrogen bond between protons and oxygen of perchlorate ion in complexes $\mathrm{H}_{4} \mathrm{TPP}^{2+} \cdot 2 \mathrm{ClO}_{4}{ }^{-}$and $\mathrm{H}_{4} \mathrm{OEP}^{2+} \cdot 2 \mathrm{ClO}_{4}{ }^{-}$is about $2 \AA^{[5]}$

The difference in the hydrogen bond length reflects the different value of the complexation constant due to dissimilarity of the properties of both porphyrin molecules and ligating ions. For the porphyrin under investigation, the complexation constant with halide ions decreases in the order $\mathrm{Cl}^{-}>\mathrm{Br}^{-}>\mathrm{I}^{-}$(see Table). Relatively low complexation constant for $\mathrm{H}_{4} \mathrm{P}^{2+} \cdot 2 \mathrm{I}^{-}$complex may lead to the fluctuations of the hydrogen bond H...I length in the solution as well the deviations from the symmetrical structure of the complex. The substantial broadening of the $\mathrm{H}_{4} \mathrm{P}^{2+} \cdot 2 \mathrm{I}^{-}$complex absorption spectrum (Figure $4 A$ and $7 B$ ) as compared with that of uncomplexed $\mathrm{H}_{4} \mathrm{P}^{2+}$ molecule seems to be explained from that point of view. Thus, for the $\mathrm{H}_{4} \mathrm{P}^{2+} \cdot 2 \mathrm{Br}^{-}$complex the broadening of the absorption spectrum is distinctly less (Figure $4 B$ ), and for the $\mathrm{H}_{4} \mathrm{P}^{2+} \cdot 2 \mathrm{Cl}^{-}$complex it is vanishing (Figure 4C).

According to the X-ray data analysis for the diprotonated form $\mathrm{H}_{2} \mathrm{OEP}$ with perchlorate ions $\left(\mathrm{H}_{4} \mathrm{OEP}^{2+} \cdot 2 \mathrm{ClO}_{4}^{-}\right)$the average value of dihedral angle $\theta$ between the planes of the pyrrolic rings and mean porphyrin plane is about $14^{\circ},{ }^{[5]}$ and the dihedral angle value depends on the interaction force between the ions in the complex. ${ }^{[3,5,15]}$ Therefore, the long wavelength shift in the electronic absorption spectrum upon the formation of $\mathrm{H}_{4} \mathrm{P}^{2+} \cdot 2 \mathrm{I}^{-}$complex seems to be due to the increase in the tilting angle $\theta$, i.e. results from an increase of the degree of the tetrapyrrolic macrocycle distortion upon complexation. This suggestion is in line with the results of quantumchemical calculations, reported recently. ${ }^{[12,15,16]}$

\section{Steady State and Time-Resolved Fluorescence}

As it was stated above, the formation of the $\mathrm{H}_{4} \mathrm{P}^{2+} \cdot 2 \mathrm{I}^{-}$complexes upon increase of the $\mathrm{KI}$ concentration in the solution leads to the long wave- length shift of $Q$-bands in the electronic absorption spectra and the changes of their spectral profiles. The absorption spectrum of $\mathrm{H}_{4} \mathrm{P}^{2+}$ has two distinct $Q$-bands with maxima at 548 and $592 \mathrm{~nm}$. The $\mathrm{H}_{4} \mathrm{P}^{2+} \cdot 2 \mathrm{I}^{-}$ complexes at $0.01 \mathrm{M}$ concentration of $\mathrm{KI}$ show the diffusive spectrum with band maximum at $559 \mathrm{~nm}$ with a weak shoulder at $605-606 \mathrm{~nm}$. Complex formation also leads to the substantial decrease in the intensity of the Soret band and small long wavelength shift of the maximum (1 nm at $0.01 \mathrm{M}$ concentration of $\mathrm{KI})$.

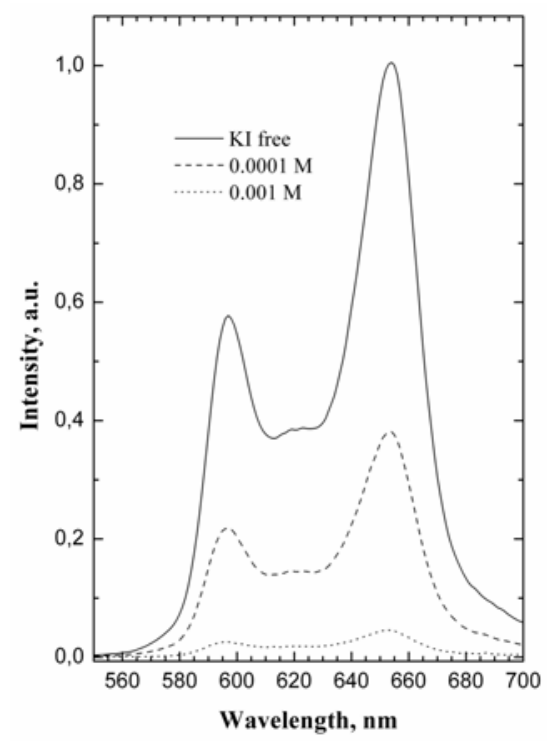

Figure 6. Fluorescence spectra of $\mathrm{H}_{4} \mathrm{P}^{2+}$ as a function of KI concentration in acetonitrile; $\lambda_{\mathrm{exc}}=400 \mathrm{~nm}$.

The fluorescence spectrum of the diprotonated $\mathrm{H}_{4} \mathrm{P}^{2+}$ form has two sharp bands with maxima at 597 and $654 \mathrm{~nm}$ (Figure 6). The fluorescence quantum yield $\Phi_{\mathrm{fl}}$ of the diprotonated $\mathrm{H}_{4} \mathrm{P}^{2+}$ form in the halide salts free solution is 0.11 . The strong fluorescence intensity decrease is observed upon formation of the complexes $\mathrm{H}_{4} \mathrm{P}^{2+} \cdot 2 \mathrm{I}^{-}$upon increase of KI concentration in the solution (Figure 6). At $0.01 \mathrm{M}$ concentration of $\mathrm{KI}$ the integral fluorescence intensity is reduced for more than 300 times. Upon this fluorescence quenching the shape of the fluorescence spectrum remains the same.

The fluorescence excitation spectra have been measured in the $Q$-band region for the salts free sample and for the solutions with $3 \cdot 10^{-4}$ and $1 \cdot 10^{-3} \mathrm{M}$ concentration of KI. All three spectra are identical (Figure 7A) and the maxima positions in the fluorescence excitation spectra were found at $\sim 548$ and $\sim 592 \mathrm{~nm}$, as it was found for the absorption spectrum of uncomplexed $\mathrm{H}_{4} \mathrm{P}^{2+}$ molecules (Figure 7B).

This finding indicates that fluorescence belongs to the uncomplexed diprotonated $\mathrm{H}_{4} \mathrm{P}^{2+}$ form, and the fluorescence of complexes $\mathrm{H}_{4} \mathrm{P}^{2+} \cdot 2 \mathrm{I}^{-}$is not observed. In other words, the complexed porphyrin $\mathrm{H}_{4} \mathrm{P}^{2+} \cdot 2 \mathrm{I}^{-}$is nonfluorescent. If we neglect the contribution into the emission from the minor concentration of uncomplexed diprotonated form $\mathrm{H}_{4} \mathrm{P}^{2+}$ in $0.01 \mathrm{M} \mathrm{KI}$ solution, ${ }^{[31]}$ the upper limit of the fluorescence quantum yield $\Phi_{\mathrm{fl}}$ for $\mathrm{H}_{4} \mathrm{P}^{2+} \cdot 2 \mathrm{I}^{-}$complex can be estimated as low as $3.6 \cdot 10^{-4}$.

The fluorescence time decay $\left(\lambda_{\text {exc }}=410 \mathrm{~nm}\right.$, 
$A$

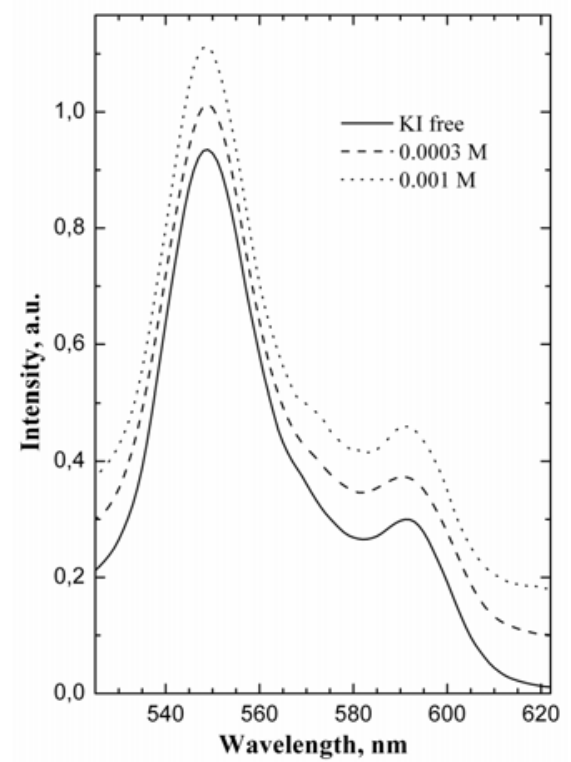

B

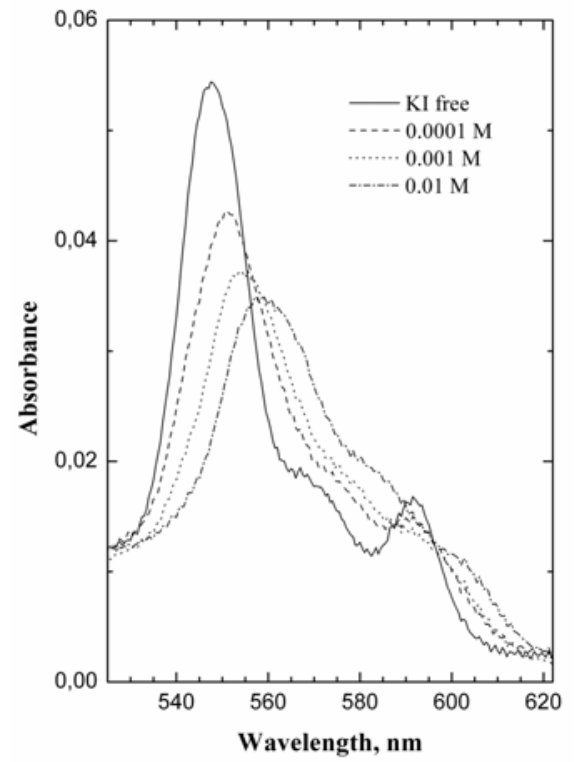

Figure 7. $A$ - Excitation fluorescence spectra of $\mathrm{H}_{4} \mathrm{P}^{2+}$ as a function of KI concentration in acetonitrile; $\lambda_{\text {obs }}=654 \mathrm{~nm}$. The spectra are shifted up for 0.1 arbitrary units each for clarity sake; $B$ - Electronic absorption spectra of $\mathrm{H}_{4} \mathrm{P}^{2+}$ as a function of KI concentration in acetonitrile; porphyrin concentration is $1.9 \cdot 10^{-6} \mathrm{M}$.

$\left.\lambda_{\mathrm{em}}=595 \mathrm{~nm}\right)$ has monoexponential character for all the solutions studied. The fluorescence lifetime $\tau_{\mathrm{fl}}$ progressively decreases in going from the salt free solution to solutions containing KI (Figure 8). For the initial solution of $\mathrm{H}_{4} \mathrm{P}^{2+}$ (without KI) the fluorescence lifetime $\tau_{\mathrm{fl}}$ is found to be $5.86 \pm 0.05 \mathrm{~ns}$, and $\tau_{\mathrm{fl}}$ value is reduced down to $3.80 \pm 0.05 \mathrm{~ns}$ at $0.002 \mathrm{M}$ concentration of KI.

\section{Static and Dynamic Fluorescence Quenching}

As it was shown above, the fluorescence of diprotonated form is efficiently quenched by iodide ions. The Stern-Volmer plot (Figure 9) deviates from the

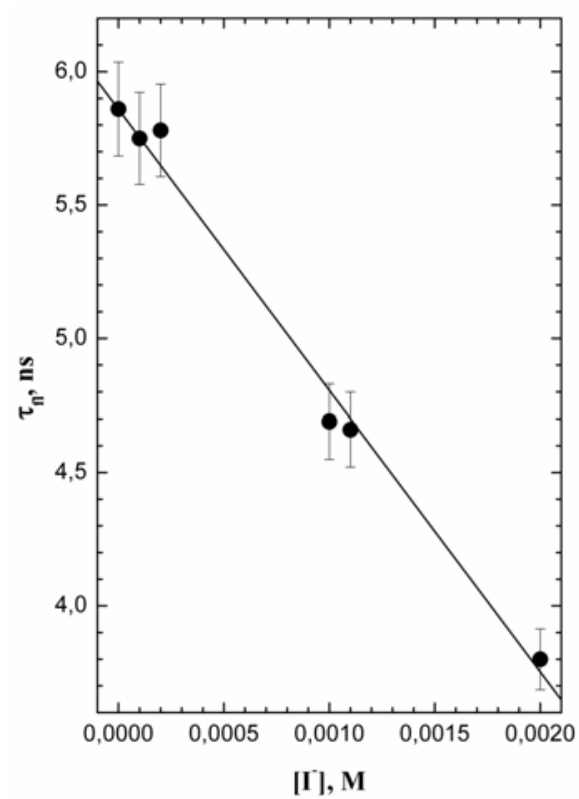

Figure 8. Fluorescence lifetime $\tau_{\mathrm{fl}}$ as a function of KI concentration in acetonitrile; $\lambda_{\mathrm{exc}}=410 \mathrm{~nm}, \lambda_{\mathrm{obs}}=595 \mathrm{~nm}$. "classical" linear dependence. The concavity of SternVolmer plot with regard to the ordinate axis is an indication that both static and dynamic diffusion-controlled quenching take place simultaneously. ${ }^{[46]}$ Concaving up is because the quenching in such a case is the second order function of iodide ion concentration

$$
I_{0} / I=1+\left(K_{\mathrm{SV}}^{\mathrm{c}}+K^{\mathrm{d}} \mathrm{SV}^{\mathrm{d}}\right)\left[\mathrm{I}^{-}\right]+K_{\mathrm{SV}}^{\mathrm{c}} K_{\mathrm{SV}}^{\mathrm{d}}\left[\mathrm{I}^{-}\right]^{2},
$$

where $K_{S V}^{\mathrm{c}}$ is the Stern-Volmer constant for the static fluorescence quenching, $K^{\mathrm{d}}{ }_{\mathrm{SV}}$ is the Stern-Volmer constant for the dynamic fluorescence quenching and $\left[\mathrm{I}^{-}\right]$is concentration iodide ion. The calculated Stern-Volmer constant $K_{\text {Sv }}^{\mathrm{c}}$ of the static fluorescence quenching due to

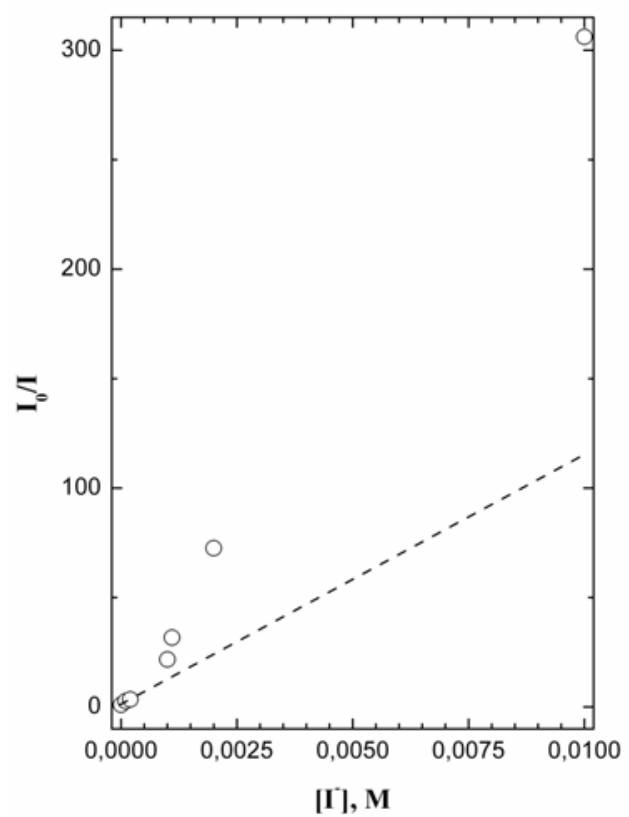

Figure 9. The Stern-Volmer plot for the fluorescence quenching of $\mathrm{H}_{4} \mathrm{P}^{2+}$ with iodide ions in acetonitrile. 

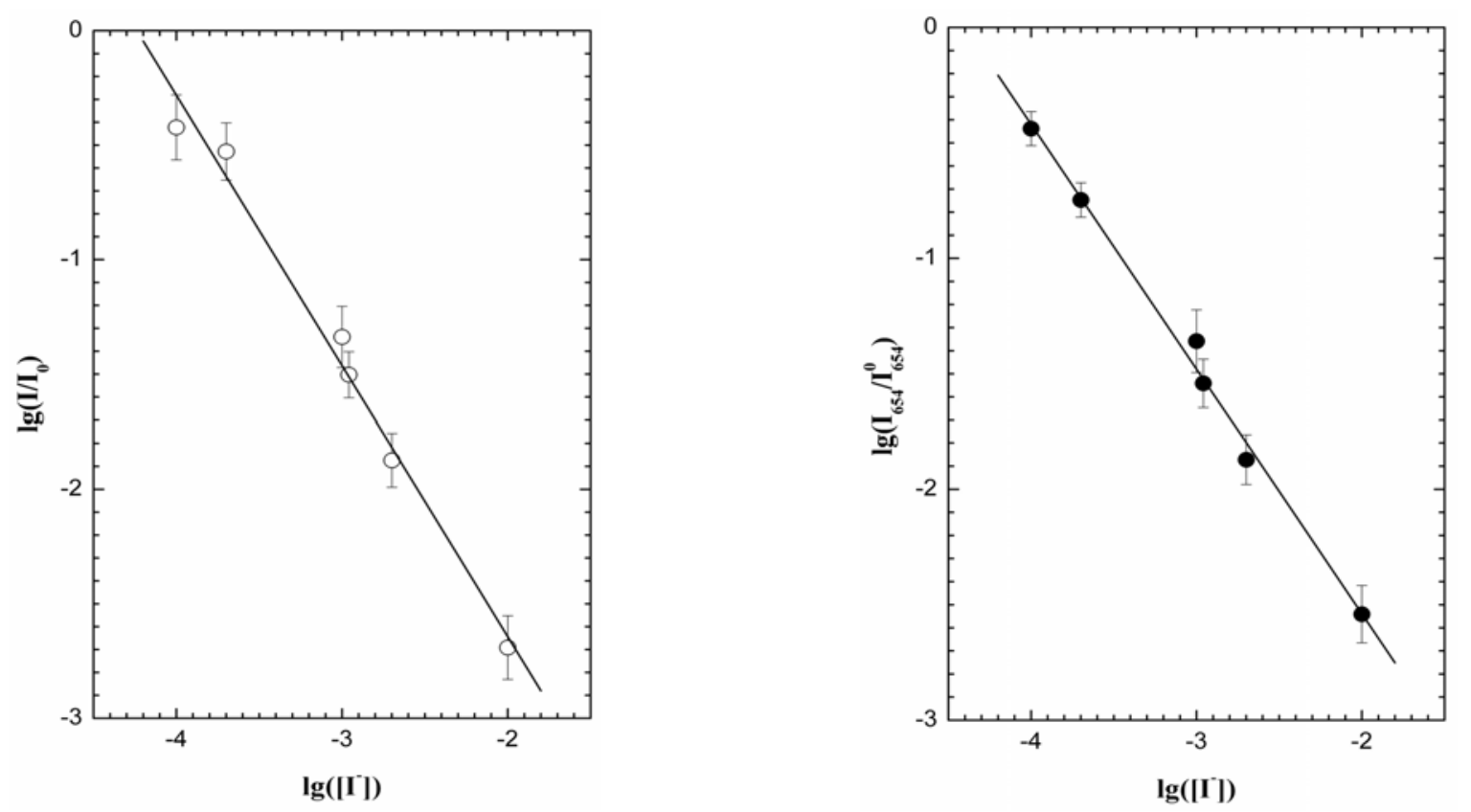

Figure 10. Double logarithmic plot for: $A$ - the integral fluorescence intensity ratio $I / I_{0}, B$ - the peak intensity ratio $I_{654} / I_{654}^{0}$ as a function of KI concentration.

complex formation with iodide-ions is $7860 \mathrm{M}^{-1}$. Fluorescence of diprotonated form of porphyrin in the complex with iodide-ions is quenched by mechanism of the internal heavy atom effect. ${ }^{[4]}$ The above data on the electronic absorption spectra and fluorescence intensity as the functions of the concentration of iodide ions in the solution indicate that the fluorescence quenching is practically parallel to the formation of the nonfluorescent $\mathrm{H}_{4} \mathrm{P}^{2+} \cdot 2 \mathrm{I}^{-}$complexes, i.e. static quenching due to the complexation with halide ions is a dominating channel of the fluorescence quenching of the $\mathrm{H}_{4} \mathrm{P}^{2+}$ molecule.

At the same time the shortening of the fluorescence lifetime of "halide ion free" diprotonated $\mathrm{H}_{4} \mathrm{P}^{2+}$ form cannot be explained with the static quenching due to internal heavy atom effect. The dependence of the fluorescence lifetime on the concentration of iodide ions $\mathrm{I}^{-}$in the solution is linear one (Figure 8). This fact indicates that the quenching can be described with Stern-Volmer approach. ${ }^{[46]}$ Therefore, one can state that the dynamic diffusion-controlled fluorescence quenching due to external heavy atom effect coexists with the static quenching due to complex formation. The SternVolmer constant $K_{\text {SV }}^{\mathrm{d}}$ of the dynamic fluorescence quenching by iodide-ions $277 \mathrm{M}^{-1}$ has been calculated with an equation

$$
\tau_{\mathrm{fl}}^{0} / \tau_{\mathrm{fl}}=1+K_{\mathrm{SV}}^{\mathrm{d}}\left[\mathrm{I}^{-}\right]
$$

where $\tau_{\mathrm{fl}}^{0}$ and $\tau_{\mathrm{fl}}$ are the fluorescence lifetimes measured in the absence of quencher and with halide salts added in the solution, respectively. The calculated $K_{\text {Sv }}^{\mathrm{d}}$ value for the dynamic quenching is almost 30 times smaller than that for the static quenching. This finding proves once more that the formation of the nonfluorescent complexes with halide ions is the dominating channel of the $\mathrm{H}_{4} \mathrm{P}^{2+}$ porphyrin fluorescence quenching by halide ions.

\section{Determination of the Iodide Ion Concentration}

The concentration dependencies of both the integral fluorescence intensity and peak fluorescence intensity at $\lambda=654 \mathrm{~nm}$ are shown in Figure 10. The double logarithmic plot is an analogue of the Scatchard plot, which is used widely in the fluorometric analysis of the ligand binding at the different hosts. ${ }^{[47,48]}$ The both plots demonstrate the linear character and can be proposed as the calibration for the iodide ion concentration measurements in the solution. ${ }^{[32,49]}$ In order to measure the iodide ions concentration the integral fluorescence intensity $I_{0}$ for the reference sample and intensity $I$ for the studied sample with unknown iodide ion concentration should be measured first. Then the $I_{0} / I$ ratio is calculated. The iodide ion concentration (in $\mathrm{M}$ ) is available from the calibration formula (6)

$$
\left[\mathrm{I}^{-}\right]=10^{\left(0.84 \lg \left(I_{0} / I\right)-4.24\right)}
$$

In a similar manner, the halide ion concentration can be determined with the ratio $I_{654}^{0} / I_{654}$ of the peak fluorescence intensities at $654 \mathrm{~nm}$ for the studied and reference samples. With this approach the iodide ion concentration (in $\mathrm{M}$ ) in the solution is given from the calibration formula (7)

$$
\left[\mathrm{I}^{-}\right]=10^{\left(0.94 \lg \left(I^{0}{ }_{654} / I_{654}\right)-4.40\right)}
$$

Moreover, the iodide ion concentration can also be determined with the measured concentration dependence of porphyrin fluorescence lifetime $\tau_{\mathrm{fl}}$ (see Figure 8). The measurements of the fluorescence time decay can be achieved at any given wavelength in the range from 560 to $720 \mathrm{~nm}$. The concentration of iodide ions (in M) is given as

$$
\left[\mathrm{I}^{-}\right]=0.0055-0.00095 \tau_{\mathrm{fl}},
$$

where $\tau_{\mathrm{fl}}$ is the fluorescence lifetime in nanoseconds.

\section{Conclusions}

The philosophy of measurements described above underlies the submitted Russian Federation patent pending. ${ }^{[49]}$ The proposed methods allow the determination of the iodide ions in the concentration range from 
$3.0 \cdot 10^{-2} \mathrm{M}$ to $3.0 \cdot 10^{-5} \mathrm{M}$. As far as we know, the luminescent methods for the iodide ion concentration measurements described to date provide the sensitivity not higher than $1.5 \cdot 10^{-4} \mathrm{M}^{[50]}$ Therefore, the developed approach seems to be promising way to increase the sensitivity of the luminescent methods of the halide ion determination in the solutions.

The additional advantage of the proposed method is the possibility to carry out the measurements in the airequilibrated solutions. The upper limit of the SternVolmer constant $K_{\mathrm{SV}}$ for the fluorescence quenching by molecular oxygen do not exceed $100 \mathrm{M}^{-1}\left(K_{\mathrm{SV}}=\tau_{\mathrm{fl}}^{0} k_{\mathrm{q}}\right.$, where $k_{\mathrm{q}}$ is a bimolecular rate constant of the fluorescence quenching by molecular oxygen). This value is almost two orders of magnitude smaller than Stern-Volmer constant $K_{\mathrm{SV}}^{\mathrm{d}}$ dominating in the fluorescence quenching by iodide ions. Therefore, the interfering influence of fluorescence quenching by molecular oxygen can be neglected.

The presented results demonstrate that diprotonated form of 3,7,13,17-tetramethyl-2,8,12,18-tetrabutylporphyrin can be used as a basic compound for the design of the luminescent molecular sensor for the measurements of the halogenide ion concentration in the solution. The diprotonated porphyrin binds the halide ions with equilibrium constant of order $10^{3}-10^{5} \mathrm{M}^{-1}$. The fluorescence of porphyrin molecule was shown is quenched by halide ions due to both external and internal heavy atom effect. The methods for measurements of the iodide ion concentration using the fluorescence quenching of diprotonated porphyrin by halide ions have been proposed. These methods allow the ions to be detected in the airequilibrated solutions at room temperatures in the wide concentration range.

Acknowledgments. This work was supported by Russian Academy of Sciences (program №7 «Chemistry and physical chemistry of supramolecular systems and atomic clusters», Russian Foundation for Basic Research (grants №№ 08-03-00009 and 08-03-90000-Bel.) and Foundation for Fundamental Research of the Republic of Belarus (project Ch08R-033).

\section{References}

1. Koifman O.I., Mamardashvili N.Zh, Antipin I.S. Synthetic Receptors on Basis of Porphyrin-calix-[4]-arene Conjugates. Moscow, Science, 2006. 249.

2. Bianchi E., Bowman-James K., Garcia-Espana E. Supramolecular Chemistry of Anions. New-York, Wiley$\mathrm{VCH}$, 1997. 461.

3. Stone A., Fleischer E.B. J. Am. Chem. Soc. 1968, 90, 27352748.

4. Gradushko A.T., Knuykshto V.N., Solovyov K.N., Tsvirko M.P. J. Applied Spectroscopy 1975, 23, 444-452.

5. Cheng B., Munro O.Q., Marques H.M., Scheidt W.R. J. Am. Chem. Soc. 1997, 119, 10732-10742.

6. Chida Y., Wararai H. Bull. Chem. Soc. Jpn. 1996, 69, 341347.

7. Zhang Y., Li M.X., Lii Y., Yang R.H., Liu F., Li K.A. J. Phys. Chem. A 2005, 109, 7442-7448.

8. Senge M.O. J. Photochem. Photobiol. B: Biol. 1992, 16, 3-36.
9. Milgrom L.R. The Colours of Life: Introduction to the Chemistry of Porphyrins and Related Compounds. Oxford: Oxford University Press, 1997. 249 p.

10. Shelnutt J.A., Song X.-Z., Ma J.-G., Jia S.-L., Jentzen W., Medforth C.J. Chem. Soc. Rev. 1998, 27, 31-41.

11. Gael V.I., Kuzmitsky V.A., Solovyov K.N. J. Applied Spectroscopy 1999, 66, 559-562.

12. Gael V.I., Kuzmitsky V.A., Solovyov K.N. J. Applied Spectroscopy 2000, 67, 696-702.

13. Ma S.Y. Chem. Phys. Lett. 2000, 332, 603-610.

14. Chen D.-M., Liu X., He T.-J., Liu F.-C. Chem. Phys. 2003, 289, 397-407.

15. Rosa A., Ricciardi G., Baerends E.J., Romeo A., Scolaro L.M. J. Phys. Chem. A 2003, 107, 11468-11482.

16. Rosa A., Riccardi G., Baerends E.J. J. Phys. Chem. A 2006, 110, 5180-5190.

17. Phillips J.N. Physico-Chemical Properties of Porphyrins, in Comprehensive Biochemistry Vol. 9 (Florkin M., Stotz E., Eds.) Amsterdam, Elsevier, 1963. 34-73.

18. Fleischer E.B., Webb L.E. J. Phys. Chem. 1963, 67, 1131-1133.

19. Hambright P., Fleischer E.B. Inorg. Chem. 1970, 9, $1757-$ 1761.

20. Gensch T., Viappiani C., Braslavsky S. J. Am. Chem. Soc. 1999, 121, 10573-10582.

21. Kruk M.M., Braslavsky S.E. J. Phys. Chem. A 2006, 110, 3414-3425.

22. Knyukshto V.N., Solovyov K.N., Egorova G.D. Biospectroscopy 1998, 4, 121-133.

23. Chirvony V.S., van Hoek A., Galievsky V.A., Sazanovich I.V., Schaafsma T.J., Holten D. J. Phys. Chem. B 2000, 104, 9909-9917.

24. Avilov I.V., Panarin A.Yu., Chirvony V.S. Chem. Phys. Lett. 2004, 389, 352-358.

25. Ogoshi H., Watanabe E., Yoshida Z. Tetrahedron 1973, 29, 3241-3245.

26. Tsvirko M.P., Solovyov K.N., Knuykshto V.N., Gradushko A.T. J. Applied Spectroscopy 1975, 23, 643-647.

27. De Luca G., Romeo A., Scolaro L.M., Ricciardi G., Rosa A. Inorg. Chem. 2007, 46, 5979-5988.

28. Saini G.S.S., Sharma S., Kaur S., Tripathi S.K., Mahajan C.G. Spectrochimica Acta Part A 2004, 61, 3070-3076.

29. Saini G.S.S. Medhi O.K., Verma A.L. Chem. Phys. Lett. 2000, 322, 293-299.

30. Ivanova Yu.B., Sheinin V.B., Berezin B.D. Russ. J. Anal. Chem. 1993, 48, 1205-1209.

31. Ivanova Yu.B., Sheinin V.B., Mamardashvili N.Zh. Russ. J. Gen. Chem., 2007, 77, 1561-1568.

32. Kruk M.M., Starukhin A.S., Mamardashvili N.Zh., Sheinin V.B., Ivanova Yu.B. J. Applied Spectroscopy 2007, 74, 750-755.

33. Mamardashvili N.Zh, Zdanovich S.A., Golubchikov O.A. Russ. J. Org. Chem. 1996, 32, 788-792.

34. Falk J.E. Porphyrins and Metalloporphyrins. Amsterdam, Elsevier, 1964, 231.

35. Reichardt C. Solvents and Solvent Effects in Organic Chemistry, 2nd ed. Weinheim, VCH Publishers, 1988. 736.

36. Viynik I.N., Golnovach A.M., Shkodin A.M. Russ. J. Phys. Chem. 1977, 51, 485-487.

37. Safonova L.P., Patsatsiyia B.K., Kolker A.M. Russ. J. Phys. Chem. 1992, 66, 2201-2208.

38. Janz G., Tomkins P. Nonaqueous Electrolytes Handbook, Vols. 1-2. London, The Chemical Society, Burlington House, 1972, 192

39. Evans D., Zawoyski C., Kay R. J. Phys. Chem. 1965, 69, 3878-3885.

40. Demas J.N., Crosby G.A. J. Phys. Chem. 1971, 75, 991-1024.

41. Seybold P., Gouterman M. J. Mol. Spectroscopy. 1969, 31, 1-11.

42. Kolthoff I.M., Chantooni M.K. J. Am .Chem. Soc. 1965, 87 , $4428-4436$ 
Halide Ions Recognition with Diprotonated Porphyrin

43. Kolthoff I.M., Chantooni M.K. J. Anal. Chem. 1967, 39, 1627-1634.

44. Bernstein I.I., Kaminskiy Yu.L. Spectrophotometric Analysis in Organic Chemistry. Leningrad, Khimia, 1986, 199. (in Russ.).

45. Kolthoff I.M., Bruckenstein S., Chantooni M.K. J. Am. Chem. Soc. 1961, 83, 3927-3935.

46. Lakowicz J.R. Principles of Fluorescent Spectroscopy. New York, Plenum Press, 1983. 496.
47. Aveline B.M., Hasan T., Redmond R.W. J. Photochem. Photobiol. B: Biol. 1995, 30, 161-169.

48. Cohen S., Margolit R. Biochem. J. 1990, 270, 325-330.

49. Kruk M.M., Starukhin A.S., Mamardashvili N.Zh., Sheinin V.B., Ivanova Yu.B. Russian Federation patent pending, № 2007122152 from 13.06.2007.

50. Eggins B. Chemical Sensors and Biosensors. Chichester, John Wiley \& Sons, 2002, 335.

Received 23.03.2008

Accepted 15.05.2008 